\title{
Anatomia e Histoquímica dos Órgãos Vegetativos DE Siegesbeckia orientalis (ASTERACEAE) ${ }^{1}$
}

\author{
Anatomy and Histochemistry of the Vegetative Organs of Siegesbeckia orientalis (Asteraceae)
}

\author{
AGUILERA, D.B. ${ }^{2}$, MEIRA, R.M.S.A. ${ }^{3}$ e FERREIRA, F.A. ${ }^{4}$
}

\begin{abstract}
RESUMO - Descreveu-se a anatomia dos órgãos vegetativos de S. orientalis, em estrutura primária, enfatizando a caracterização e histoquímica de suas estruturas secretoras. Folhas, caules e raízes foram fixados em $\mathrm{FAA}_{50}$ e em sulfato ferroso e estocados em etanol $70 \%$. Cortes transversais e longitudinais foram submetidos ao azul-de-toluidina $\mathrm{pH} 4,0$, ao vermelho-de-rutênio, à reação de PAS, ao reativo Xylidine Ponceau, ao Sudan Black B e ao reativo Dragendorff. Anatomicamente, os órgãos vegetativos de S. orientalis são semelhantes aos caracteres descritos para Asteraceae. As raízes laterais são triarcas e o caule, um eustelo. Ductos estão ausentes na raiz e presentes no caule e na folha. Estas estruturas são de pequeno diâmetro, sendo delimitadas por quatro a cinco células epiteliais. No caule, os ductos estavam presentes no córtex, próximos à endoderme e na medula; nas folhas, associados aos feixes vasculares, tanto para o lado do xilema quanto para o do floema. As folhas são dorsiventrais e anfiestomáticas. Três tipos de estruturas secretoras foram observados: ductos, hidatódios e tricomas glandulares. Os testes histoquímicos aplicados demonstraram a presença de compostos fenólicos e alcalóides nos ductos e, nos tricomas, de compostos lipofilicos e fenólicos. Esses resultados indicam a complexidade da secreção produzida pelas estruturas secretoras na espécie.
\end{abstract}

Palavras-chave: planta daninha, planta medicinal, botão-de-ouro, Heliantheae.

ABSTRACT - The anatomy of the vegetative organs of $\mathbf{S}$. orientalis in primary structure was described, emphasizing the characterization and histochemistry of its secretory structures. Leaves, stems and roots were fixed in $F A A_{50}$ and ferrous sulphate and stored in $70 \%$ ethanol. Cross and longitudinal sections were submitted to toluidine blue $\mathrm{pH}$ 4.0, ruthenium red, PAS reaction, Ponceau Xylidine reactive, Sudan Black $B$ and Dragendorff reactive. Anatomically, S. orientalis vegetative organs are similar to the characters described for the Asteraceae. The lateral roots are triarches and the stem is an eustele. Ducts are absent in the root and present in the stem and leaf. These structures are of low diameter, being delimited by 4 to 5 epithelial cells. In the stems, the ducts were present in the cortex, next to the endoderm and in the pith. In the leaves, they were associated to the vascular bundles, facing both the xylem and the phloem. The leaves are dorsiventral and amphistomatic. Three types of secretory structures were observed: ducts, hydathodes and glandular trichomes. The histochemical tests showed the presence of phenolic and alkaloid compounds in the ducts, while lipid and phenolic compounds were found in the trichomes. Such results indicate the complex secretion produced by the structures in this species.

Key words: weed, medicinal plant, hythiem, shrimp-claw plant, Heliantheae.

Recebido para publicação em 8.10.2004 e na forma revisada em 17.12.2004.

Bolsista FAPEMIG, Doutoranda em Fitotecnia pela Universidade Federal de Viçosa - UFV, 36570-000, Viçosa-MG, <balzanelo@yahoo.com.br>; ${ }^{3}$ Professor Adjunto, Departamento de Biologia Vegetal da UFV, <rmeira@ufv.br>; ${ }^{4}$ Professor Titular, Departamento de Fitotecnia da UFV, <faffonso@ufv.br>. 


\section{INTRODUÇÃO}

Siegesbeckia orientalis, conhecida por botão-de-ouro, é uma planta herbácea anual e cosmopolita, da família Asteraceae, incluída na tribo Heliantheae. No Brasil, é considerada planta daninha, freqüentemente encontrada na região Sudeste (Kissmann \& Groth, 1992; Bremer, 1994). A parte aérea da planta é utilizada na medicina tradicional chinesa em tratamentos antialérgicos, artrites reumáticas, entre outros (Pudles et al., 1957; Baruah et al., 1979, 1980; Hwang et al., 2001), tendo sido isolados diversos compostos, que, além de possuirem principios ativos medicamentosos, incluem substâncias com atividade alelopática (Pudles et al., 1957; Bohlmann et al., 1979; Baruah et al., 1979, 1980; Zdero et al., 1991; Heinrich et al., 2002).

A Asteraceae constitui a maior família entre as Angiospermas, com cerca de 1.535 gêneros e 23.000 espécies (Bremer, 1994; Judd et al., 1999). O sucesso da família talvez se deva à presença de tipos particulares de estruturas secretoras, como canais resiniferos e laticíferos, responsáveis pela sua defesa química (Metcalfe \& Chalk, 1950; Heywood et al., 1977; Cronquist, 1981; Simões et al., 2002).

Considerando-se as investigações realizadas sobre a anatomia de Asteraceae, diferentes tipos de estruturas secretoras foram relatados: ductos (Castro, 1987; Ascensão \& Pais, 1988; Lersten \& Curtis, 1988; Meira, 1991; Claro, 1994; Poli et al., 1995; Castro et al., 1997), cavidades (Lersten \& Curtis, 1986, 1987, 1989; Curtis \& Lersten, 1986, 1990; Monteiro et al., 1995), idioblastos (Meira, 1991; Claro, 1994), laticíferos (Vertrees \& Mahlberg, 1978), hidatódios (Lersten \& Curtis, 1985; Castro, 1987; Meira, 1991; Claro, 1994; Castro et al., 1997), nectários extraflorais (O'Dowd \& Catchpole, 1983), tricomas (Werker \& Fahn, 1981; Castro, 1987; Meira, 1991; Claro, 1994; Castro et al., 1997; Monteiro et al., 2001), coléteres (Solereder, 1908) e apêndices glandulares (Carlquist, 1959). Nesses trabalhos, tais estruturas foram investigadas quanto aos aspectos estruturais, ultra-estruturais, histoquímicos e ecológicos.

Dados sobre anatomia de Siegesbeckia estão restritos às informações contidas na revisão de Solereder (1908), que relatou a ocorrência de coléteres no pecíolo, e de Heinrich et al. (2002), que observaram a presença de tricomas glandulares multicelulares de haste longa (bi a trisseriados) e pequenos tricomas bisseriados nas brácteas involucrais internas e externas dos capítulos paniculados.

O objetivo do trabalho foi descrever a anatomia dos órgãos vegetativos, em estrutura primária, de S. orientalis, enfatizando a caracterização de estruturas secretoras, e aplicar testes histoquímicos para obter informações sobre a natureza química dos produtos secretados.

\section{MATERIAL E MÉTODOS}

O material vegetal foi coletado de plantas de Siegesbeckia orientalis que cresciam espontaneamente no campus da Universidade Federal de Viçosa - UFV, Viçosa, MG. O espécime testemunha encontra-se depositado no Herbário da UFV (VIC), sob o n² 26.307.

Foram amostradas folhas totalmente expandidas, entre o quarto e o quinto nó a partir do ápice; caules em estrutura primária, localizados em entrenós acima da quarta folha; e raízes laterais de pequeno calibre próximas ao ápice meristemático, que se encontravam em estrutura primária. As amostras foram fixadas em FAA $_{50}$ (formaldeído, ácido acético glacial, etanol 50\%; 5:5:90, v/v) (Johansen, 1940) e, para verificação de compostos fenólicos, em sulfato ferroso em formalina neutra tamponada - SF (Jensen, 1962). Ambas as amostras foram estocadas em etanol $70 \%$. Cortes transversais e longitudinais do pecíolo (porções basal e distal), da lâmina foliar (porções basal, mediana, apical e marginal), dos caules e das raízes (porção apical) foram obtidos em micrótomo de mesa e em micrótomo rotativo de avanço automático (RM 2155, Leica). Neste último caso, as amostras foram incluídas em metacrilato (Historesin, Leica) e cortadas na espessura de $8 \mu \mathrm{m}$ com navalha de aço.

Os cortes das amostras fixadas em $\mathrm{FAA}_{50}$ foram submetidos aos reagentes: azul-detoluidina - AT, pH 4,0 (O'Brien \& McCully, 1981), para detecção de radicais catiônicos e metacromasia; ao vermelho-de-rutênio - VR (Johansen, 1940), que cora, principalmente, substâncias pécticas; ao reativo de Schiff 
e ácido periódico - PAS (Pearse, 1980), para identificar polissacarídeos neutros e glicoproteinas; ao reativo Xylidine Ponceau - XP (Vidal, 1970), para verificação de radicais catiônicos protéicos; ao Sudan Black B - BB (Benes, 1964), para verificação de compostos lipídicos; e ao reativo Dragendorff - DD (Yoder \& Mahlberg, 1976), para alcalóides. As lâminas preparadas com amostras cortadas ao micrótomo de mesa foram montadas em gelatina glicerinada (Johansen, 1940), e aquelas incluídas em metacrilato foram montadas em resina sintética (Permount, SP15-500, Fisher Scientific) (Ruzin, 1999). Para alguns dos testes foram desenvolvidos controles: para o PAS, pela supressão do tratamento com ácido periódico (Riding \& Gifford, Jr., 1973); para lipídios, pela extração prévia com piridina (Jensen, 1962); e para compostos fenólicos, pela extração prévia com metanol (Ramsey \& Berlyn, 1976).

$\mathrm{Na}$ análise e documentação fotográfica foram utilizados um fotomicroscópio (Olympus AX70), equipado com sistema fotográfico (U-Photo) e recurso de contraste de fase e polarização, e um microscópio estereoscópico.

\section{RESULTADOS E DISCUSSÃO}

As folhas de S. orientalis são simples, opostas em pares cruzados e com as bases dos pecíolos fundidas aos ramos.

No pecíolo, a epiderme é unisseriada, com cutícula espessa e com tricomas tectores pluricelulares unisseriados e glandulares pluricelulares bisseriados (Figura 1), com 8 a 12 células, sendo 2 basais, 2 no pescoço e 6 a 10 formando o ápice (Figura 1). Nestes últimos, as células da cabeça apresentam citoplasma denso e a cutícula que as recobre se distende, dando origem a um espaço subcuticular. Tricomas secretores bisseriados são característicos da família Asteraceae, podendo ser considerados um caráter conservativo (Castro, 1987; Meira, 1991; Claro, 1994; Castro et al., 1997; Monteiro et al., 2001). O colênquima é subepidérmico e três feixes vasculares colaterais encontram-se imersos no parênquima cortical (Figura 1). Ductos secretores de diâmetro reduzido, delimitados por 4 a 5 células epiteliais, encontram-se próximos aos feixes vasculares, tanto para o lado do floema (Figuras 1 e 2) como para o do xilema (Figuras 1 e 4). Em corte longitudinal, o lúmen dos ductos é alongado e reagiu positivamente aos testes para compostos fenólicos (Figura 3) e alcalóides. Os fenóis incluem uma grande diversidade de compostos, como os flavonóides, os taninos e os ácidos benzóicos e cinâmicos (Simões et al., 2002); estes últimos podem ser encontrados complexados com proteínas, alcalóides e terpenos (Salatino \& Gottlieb, 1980). Não foram visualizados coléteres nos pecíolos, o que se contrapõe ao relato de Solereder (1908).

O limbo é lanceolado e pubescente, com a margem serrilhada e venação reticulada. As folhas são anfiestomáticas, com estômatos do tipo anomocítico, e a epiderme é unisseriada (Figura 5). Tricomas tectores e glandulares bisseriados são abundantes por toda a superficie foliar e podem ser visualizados ao microscópio estereoscópico, como gotas translúcidas (Figura 8). Na nervura central (Figura 6), o colênquima subepidérmico se dispõe como calotas - uma voltada para a face adaxial e a outra para a abaxial. Os feixes vasculares são colaterais e delimitados pelo parênquima aclorofilado (Figura 6). Ductos secretores de lúmen reduzido estão próximos ao feixe vascular, tanto para o lado do floema quanto para o do xilema. Os plastídeos do parênquima clorofiliano e os das células-guarda dos estômatos reagiram positivamente ao teste para alcalóides (Figura 6). O mesofilo é dorsiventral, e nas nervuras de maior porte foram visualizados ductos voltados somente para a face adaxial (Figura 5). A constante presença e a posição dos ductos confirmam a sugestão de que na tribo Heliantheae essas características podem ter valor diagnóstico (Castro, 1987; Ascensão \& Pais, 1988; Lersten \& Curtis, 1988; Meira, 1991; Claro, 1994; Poli et al., 1995; Castro et al., 1997).

Hidatódios (Figuras 7 e 8) foram evidenciados nas margens das folhas. São caracterizados por uma epiderme portadora de poros, por epitema subepidérmico constituído de pequenas células de núcleo grande, citoplasma denso e aclorofiladas; a vascularização é exclusivamente xilemática. São responsáveis pelo processo de gutação e são estruturas comuns dentre as Asteraceae (Lersten \& Curtis, 1985; Castro, 1987; Meira, 1991; Claro, 1994; Castro et al., 1997).

Planta Daninha, Viçosa-MG, v. 22, 4, p. 483-489, 2004 


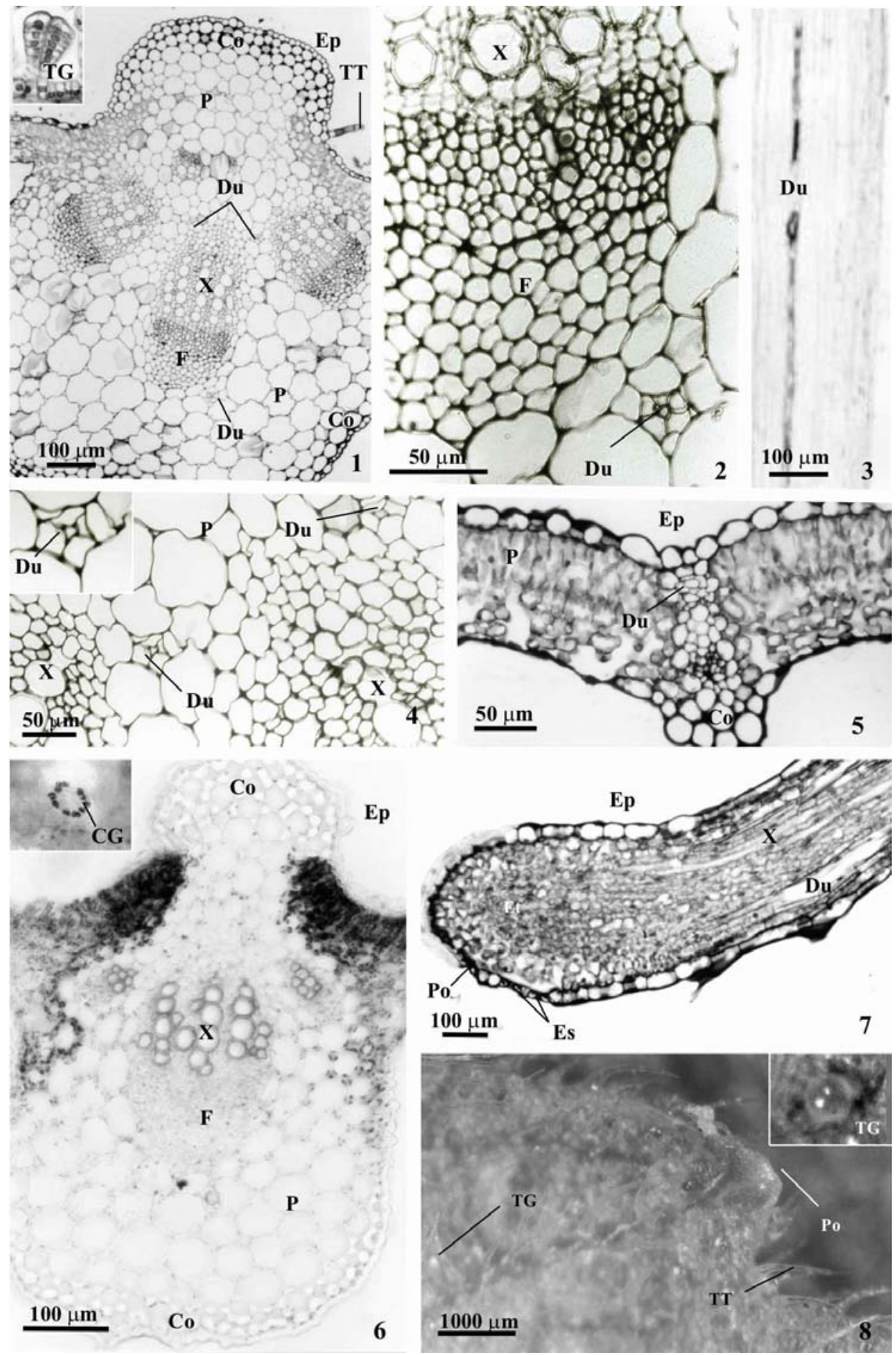

Figuras 1-8 - Cortes de Siegesbeckia orientalis. 1, 2 e 4) transversal do pecíolo; em 1, detalhe do tricoma glandular (AT), e em 4, do ducto. 3) longitudinal do pecíolo (SF). 5) transversal da nervura de maior calibre do mesofilo (AT). 6) transversal da nervura central da folha; detalhe do estômato (DD). 7) longitudinal do hidatódio na margem foliar (AT). 8) vista geral da superfície foliar em microscópio estereoscópico; detalhe do tricoma glandular. AT, azul-de-toluidina; CG, célula-guarda; Co, colênquima; DD, reagente de Dragendorff; Du, ducto; Ep, epiderme; Es, estômato; Et, epitema; F, floema; P, parênquima; Po, poro; SF, sulfato ferroso; TG, tricoma glandular; TT, tricoma tector; X, xilema. 
O caule é cilindrico, oco, de cor verde e levemente pubescente. A epiderme é unisseriada (Figura 9), com estômatos que se projetam para o exterior (Figura 10) e com os mesmos tipos de tricomas tectores e glandulares (Figuras 11 e 12) observados na folha, porém em menor abundância. O córtex é ocupado por um anel subepidérmico de quatro a cinco camadas de colênquima do tipo lamelar (Figura 9) e internamente delimitado pela endoderme (Figuras 9 e 13). Internamente ao colênquima ocorre um parênquima clorofiliano, onde se apresentam imersos ductos secretores de diâmetro reduzido, associados aos feixes vasculares, tanto para o lado do floema (Figura 9) quanto para o do xilema (Figura 14). Os feixes vasculares são colaterais, e a medula, parenquimática; caracteriza-se, portanto, estelo do tipo eustelo. O conteúdo do lúmen dos ductos e grânulos nas células da endoderme reagiu positivamente ao teste para alcalóides (Figura 13). Compostos fenólicos também foram identificados nos ductos do caule, assim como para aqueles da folha (Figura 3). Esses resultados corroboram os registrados na literatura quanto à complexidade química dos produtos secretados pelas estruturas secretoras de Asteraceae, relacionando o grande sucesso da família, a maior entre as Angiospermas, a um sistema de defesa químico derivado (Metcalfe \& Chalk, 1950; Heywood et al., 1977; Cronquist, 1981).

A espécie possui raiz pivotante, bastante desenvolvida e de coloração branca. A epiderme é uniestratificada, revestida com cutícula extremamente fina; o córtex parenquimático é delimitado internamente por uma endoderme com estrias de Caspary (Figura 15). A raiz lateral é triarca na região seccionada (Figura 15) e de maturação centrípeta. Não foram evidenciadas estruturas secretoras na raiz, o que confirma os conhecimentos da medicina popular, que indicam somente a utilização da parte aérea nos preparos medicinais (Pudles et al., 1957; Bohlmann et al., 1979; Baruah et al., 1979, 1980; Zdero et al., 1991; Heinrich et al., 2002).

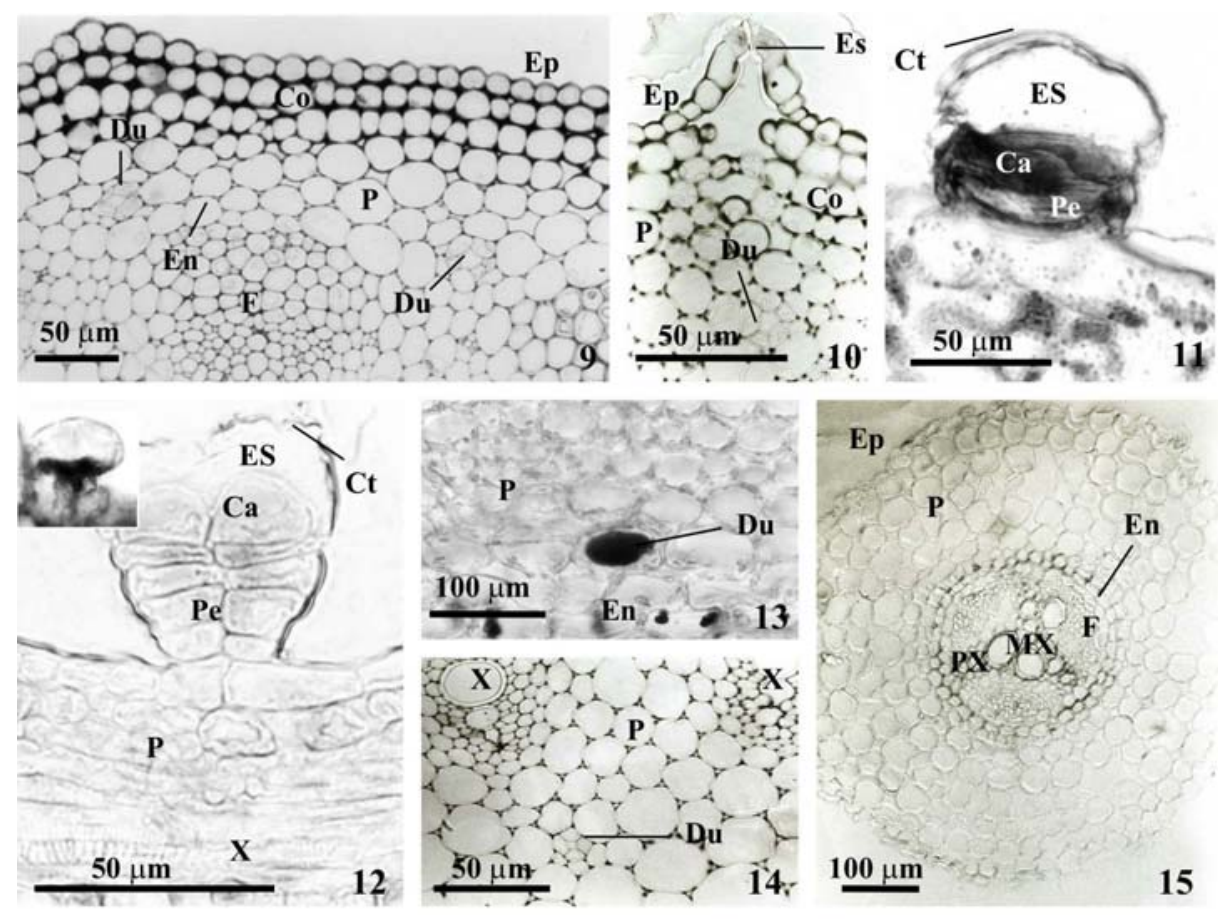

Figuras 9-15 - Cortes de Siegesbeckia orientalis. 9-10 e 14) transversal do caule (AT). 11) tricoma glandular (BB). 12) tricoma glandular e detalhe da reação (SF). 13) detalhe da reação no ducto e na endoderme (DD). 15) transversal da raiz (SF). AT, azulde-toluidina; BB, Sudan Black B; Ca, cabeça; Co, colênquima; Ct, cutícula; DD, reagente de Dragendorff; Du, ducto; En, endoderme; Ep, epiderme; Es, estômato; ES, espaço subcuticular; F, floema; MX, metaxilema; P, parênquima; Pe, pescoço; PX, protoxilema; SF, sulfato ferroso; X, xilema. 
O conteúdo dos ductos reagiu positivamente a compostos fenólicos (Figura 3) e a alcalóides (Figura 13). Quanto aos tricomas glandulares (Figuras 1, 8, 11 e 12), a reação foi positiva somente nas células da cabeça, tanto para compostos lipofilicos (Figura 11) como para fenólicos (Figura 12), evidenciando uma cutícula distendida (Figuras 11 e 12). A reação positiva para compostos lipofílicos indica que os tricomas glandulares são os responsáveis pela síntese e/ou acúmulo dos terpenóides relatados para a espécie (Pudles et al., 1957; Baruah et al., 1979, 1980; Bohlmann et al., 1979, Zdero et al., 1991; Heinrich et al., 2002). Como a espécie é cultivada como medicinal, esses dados são de importância nas decisões agronômicas de cultivo e pós-colheita (Simões et al., 2002).

O vermelho-de-rutênio e o PAS reagiram somente nas paredes celulares. O Xylidine Ponceu corou paredes celulares primárias e proteínas citoplasmáticas. Não foram evidenciadas substâncias pécticas, polissacarídeos e proteínas como conteúdo das estruturas secretoras descritas.

Siegesbeckia orientalis apresentou estruturas secretoras típicas da família Asteraceae. Dos tipos de estruturas secretoras descritas para a família, três foram observados na espécie: ductos, hidatódios e tricomas. Os testes histoquímicos demonstraram a presença de compostos fenólicos e alcalóides nos ductos e de compostos lipofílicos e fenólicos nos tricomas, indicando a complexidade da secreção produzida pela espécie e confirmando seu potencial farmacológico.

\section{LITERATURA CITADA}

ASCENSÃO, L.; PAIS, M. S. Ultrastructure and histochemistry of secretory ducts in Artemisia campestris ssp. maritima (Compositae). Nord. J. Bot., v. 8, n. 2, p. 283-292, 1988.

BARUAH, R. N. et al. A new melampolide from Siegesbeckia orientalis. Phytochemistry, v. 18, p. 991-994, 1979.

BARUAH, R. N. et al. New melampolides and darutigenol from Siegesbeckia orientalis. Phytochemistry, v. 19, p. 323-325, 1980.

BENES, K. Detection of lipids in plant meristematic cell with aid of sudan black staining. Biol. Plant., v. 6, n. 1, p. 142-151, 1964.

Planta Daninha, Viçosa-MG, v. 22, n. 4, p. 483-489, 2004
BREMER, K. Asteraceae, cladistics \& classification. Portland: Timber Press, 1994. 752 p.

BOHLMANN, F. et al. Neue melampolide und cis, cisgermacranolide aus vertretern der subtribus Melampodiinae. Phytochemistry, v. 18, p. 625-630, 1979.

CARLQUIST, S. The leaf of Calycadenia and its glandular appendages. Am. J. Bot., v. 46, p. 70-80, 1959.

CASTRO, M. M. Estruturas secretoras em folhas de espécies da família Asteraceae: aspectos estruturais e histoquímicos. 1987. 247 f. Tese (Doutorado em Botânica) - Universidade de São Paulo, São Paulo, 1987.

CASTRO, M. M.; LEITÃO-FILHO, H. F.; MONTEIRO, W. R. Utilização de estruturas secretoras na identificação dos gêneros de Asteraceae de uma vegetação de cerrado. R. Bras. Bot., v. 20, n. 2, p. 163-174, 1997.

CLARO, S. M. C. A. Levantamento dos tipos de estruturas secretoras em folhas de Asteraceae da restinga de Setiba, Guarapari (ES). 1994. $101 \mathrm{f}$. Dissertação (Mestrado em Biologia Vegetal) - Universidade Estadual de Campinas, Campinas, 1994.

CRONQUIST, A. An integrated system of classification of flowering plants. New York: Columbia University Press, 1981. $1262 \mathrm{p}$.

CURTIS, J. D.; LERSTEN, N. R. Development of bicellular foliar secretory cavities in white snakeroot, Eupatorium rugosum (Asteraceae). Am. J. Bot., v. 73, n. 1, p. 79-86, 1986.

CURTIS, J. D.; LERSTEN, N. R. Oil reservoirs in stem, rhizome, and root of Solidago canadensis (Asteraceae, tribe Astereae). Nord. J. Bot., v. 10, n. 4, p. 443-449, 1990.

HEINRICH, G. et al. Glandular hairs of Siegebeckia jorullensis Kunth (Asteraceae): morphology, histochemistry and composition of essential oil. Ann. Bot., v. 89, n. 4, p. 459-469, 2002.

HEYWOOD, V. H.; HARBONE, J. B.; TURNER, B. L. The biology and chemistry of the Compositae. London: Academic Press, 1977. v. 1. 619 p.

HWANG, W. J. et al. Inhibitory effect of immunoglobulin and production by jin-deuk-chal (Siegesbeckia orientalis). Immunopharmacol. Immunotoxicol., v. 23, n. 4, p. 555$563,2001$.

JENSEN, W. A. Botamical histochemistry: principles and practice. San Francisco: W.H. Freeman and Company, 1962. 408 p.

JOHANSEN, D. A. Plant microtechnique. New York: Mcgraw-Hill Book, 1940. 523 p. 
JUDD, W. S. et al. Plant systematics, a phylogenetic approach. Massachusetts: Publishers Sunderland, 1999. $464 \mathrm{p}$.

KISSMANN, K. G.; GROTH, D. Plantas infestantes e nocivas. São Paulo: BASF Brasileira, 1992. v. 2. p. 326328.

LERSTEN, N. R.; CURTIS, J. D. Distribution and anatomy of hydathodes in Asteraceae. Bot. Gaz., v. 146, n. 1, p. 106114, 1985.

LERSTEN, N. R.; CURTIS, J. D. Tubular cavities in white snakeroot, Eupatorium rugosum (Asteraceae). Am. J. Bot., v. 73, n. 1, p. 1016-1021, 1986.

LERSTEN, N. R.; CURTIS, J. D. Internal secretory spaces in Asteraceae. A review and original observations on Conyza canadensis (tribe Astereae). La Cellule, v. 74, p. 179-196, 1987.

LERSTEN, N. R.; CURTIS, J. D. Secretory reservoirs (ducts) of two kinds in giant ragweed (Ambrosia trifida; Asteraceae). Am. J. Bot., v. 75, n. 1, p. 1313-1323, 1988.

LERSTEN, N. R.; CURTIS, J. D. Foliar oil reservoir anatomy and distribution in Solidago canadensis (Asteraceae, tribe Astereae). Nord. J. Bot., v. 9, n. 2, p. 281-287, 1989.

MEIRA, R. M. S. A. Levantamento dos tipos de estruturas secretoras em folhas de espécies de Asteraceae em vegetação de floresta (Atibaia, SP). 1991. 99 f. Dissertação (Mestrado em Biologia Vegetal) Universidade Estadual de Campinas, Campinas, 1991.

METCALFE, C. R.; CHALK, L. Anatomy of dicotyledons. Oxford: Clarendon Press, 1950. v. 2. 724 p.

MONTEIRO, W. R.; CASTRO, M. M.; FAHN, A. Observations on the development of foliar secretory cavities of Porophyllum lanceolatum (Asteraceae). Nord. J. Bot., v. 15, n. 1,p. 69-76, 1995.

MONTEIRO, W. R. et al. Development and some histochemical aspects of foliar glandular trichomes of Stevia rebaudiana (Bert.) Bert. - Asteraceae. R. Bras. Bot., v. 24, n. 3, p. 349-357, 2001.

O'BRIEN, T. P.; McCULLY, M. E. The study of plant structure: principles and selected methods. Melbourne: Termarcarphi Pty, 1981. 316 p.

O’DOWD, D. J.; CATCHPOLE, E. A. Ants and extrafloral nectaries: no evidence for plant protection in Helichrysum ssp. - ant interactions. Oecologia, v. 59, n. 2, p. 191-200, 1983.
PEARSE, A. G. E. Histochemistry, theoretical and applied: preparative and optical technology. 4.ed. Edinburgh: Churchill Livingston, 1980. v. 1. 439 p.

POLI, F.; SACCHETTI, G.; BRUNI, A. Distribution of internal secretory structures in Tagetes patula (Asteraceae). Nord. J. Bot., v. 15, n. 2, p. 197-205, 1995.

PUDLES, J.; DIARA, A.; LEDERER, E. Sur l'isolement et la constitution chimique du darutoside, principe amer de Siegesbeckia orientalis. Comp. Rend., v. 244, n. 4, p. 472475, 1957.

RAMSEY, J. C. ; BERLYN, J. D. Ultrastructure of early stages of cotton fiber differentiation. Bot. Gaz., v. 137, n. 1, p. 11-19, 1976.

RIDING, R. T.; GIFFORD JR., E. M. Histochemical changes occurring at the seedling shoot apex of Pinus radiate. Canad. J. Bot., v. 51, p. 501-512, 1973.

RUZIN, S. E. Plant microtechnique and microscopy. New York: Oxford University Press, 1999. 322 p.

SALATINO, A.; GOTTLIEB, O. R. Quinolizidine alkaloids as systematic markers of the Papilionoideae. Bioch. Syst. Ecol., v. 8, n. 1, p. 133-147, 1980.

SIMÕES, C. M. O. et al. Farmacognosia: da planta ao medicamento. Florianópolis: Universidade Federal de Santa Catarina, 2002. 833 p.

SOLEREDER, H. Systematic anatomy of the dicotyledons - A handbook for laboratories of pure and applied botany. Oxford: Clarendon Press, 1908. v. 2. $1182 \mathrm{p}$.

VERTREES, G. L.; MAHLBERG, P. G. Structure and ontology of laticifers in Cichorium intybus (Compositae). Am. J. Bot., v. 65, p. 764-771, 1978.

VIDAL, B. C. Dichroism in collagen bundles stained with Xylidine Ponceau 2 R. Ann. Histoch., v. 15, p. 289-296, 1970.

WERKER, E.; FAHN, A. Secretory hairs of Inula viscosa (L.) Ait. - development, ultrastructure, and secretion. Bot. Gaz., v. 142, n. 4, p. 461-476, 1981.

YODER, L. R.; MAHLBERG, P. G. Reactions of alkaloid and histochemical indicators in laticifers and specialized parenchyma cells of Catharanthus roseus (Apocynaceae). Am. J. Bot., v. 63, n. 9, p. 1167-1173, 1976.

ZDERO, C. et al. Sesquiterpene lactones and other constituents from Siegesbeckia orientalis and Guizotia scabra. Phytochemistry, v. 30, n. 5, p. 1579-1584, 1991. 